\title{
The Concept of "Body" in Lao Zi
}

\author{
Zeng Weijie and An Saiping
}

\begin{abstract}
${ }^{1}$ Abstract-Rarely have been research objects more complicated and huge than "body." Modern individuals tend to view the "body" from the perspective of Western medical science in which the "body" is constantly treated in a technical or even a mechanical way. Lao $\mathrm{Zi}$ pointed out a traditional Chinese view on "body" which connected the human body to the universe thereby formed a universe in human body. Through analyzing the text of $\mathrm{Lao} \mathrm{Zi}$, this article explores the relationship between human, Dao, nature, heaven and earth in detail, and aims to grasp Lao Zi's body connotation from various dimensions. Meanwhile, through the interpretation of Lao $\mathrm{Zi}$, it reveals a view of "body" under Chinese traditional ideology and culture, in order to provide a different view of the body perceived by people from the context of the Western culture.
\end{abstract}

Index Terms - Lao Zi, body, Dao (Way), nature, heaven, earth, universe.

\section{INTRODUCTION}

The discussion about "body" has been around for a long time, and there have been numerous discussions in this matter since the "Axial Period." From the 1990s, influenced by the discussion on "body" by western scholarship, the mainland China and Taiwan have set off a wave of research on the early Chinese concept on "body." In fact, it is biased to interpret the narrative of the body in ancient Chinese culture with the Western concepts. "The body is bound by the supernatural meaning of the idea." This constraint exists both in the East and West, but differs in degree due to the dualistic and unified perspectives. [1] The West hopes to achieve the transcendence of the body through God's redemption of the human body from the top down. Although there is also a tension between "heaven and human" (天人) in ancient China, it is much softer under the monist philosophy. The root of relationship between "heaven and human" is "oneness (合一)," therefore the "body," in Chinese context, has been regarded to be able to attain transformation and transcendence without external powers or assistances like the God in Christianity.

The Chinese scholarship on the concept of body are mainly focused on the relation between "body" and "mind" insofar. Daoism adds "qi" as "qi" has been regarded as the medium for communication between "body" and "mind." The book Lao $\mathrm{Zi},{ }^{2}$ as one of the most significant classics in

Manuscript received July 9, 2018; revised December 12m 2018,

Zeng Weijie and An Saiping are with Hong Kong Polytechnic University, Hung Hom, Kowloon, Hong Kong. She is now with the Department of Chinese Culture, Hong Kong Polytechnic University. (e-mail: zeng.wj.zeng@connect.polyu.hk,sp.an@connect.polyu.hk).
Chinese culture, is also one of the representative work regarding Chinese concept "oneness (合一)." It reflects a theoretical model for Chinese traditional view on "body." Therefore, this article will proceed from a holistic view and systematically analyze and sort out the narratives about the body in Lao $\mathrm{Zi}$. The core of monism is that all ones are not divided. In terms of the thought of Lao Zi, it is regarded as “chaos (混沌)" which can be transformed into five levels: human, earth, heaven, Dao, and nature. [2] They resemble a big tree in which the branches are separated and all from one root. Man is the tangible reality of the Dao and an intermediary that connects heaven, earth, and nature. Therefore, taking the person with the shape drive as the core, this article attempts to perceive the concept of body through analyzing in detail the relationship between man, Dao, nature, heaven and earth. ${ }^{3}$ Meanwhile, through the discussion of the body of Lao $\mathrm{Zi}$ and the dialogue with Western view on body, it hopes to illustrate the difference between the interpretation of "body" in the West and that in Lao Zi.

Lao $\mathrm{Zi}$ pointed out, "the reason I have great trouble is that I have a body. When I no longer have a body, what trouble have I?" [3] Literally, this sentence may cause misunderstanding that Lao $\mathrm{Zi}$ advocated to "abandon the body." However, in fact, Lao Zi, Zhuangzi and later religious Daoism cherished the body greatly and believed that the body is the carrier of the Dao. Therefore, before the analysis on Lao Zi's view on the body, it is necessary to clarify the actual connotation of "trouble of body."

Wen Yiduo indicates that Lao $\mathrm{Zi}$ aimed to grasp the general rules of the change of the heaven and the earth, and thus achieve the purpose of "meeting no danger to the end of one's days (沒身不殆).” Despite that, the world is infinitely changing, with numerous invisible factors, this is the reason why Lao $\mathrm{Zi}$ puts forward the theory of "trouble of body." [4] The point of view Wen Yiduo actually expresses is that people should be familiar with and further apply the teachings of the Dao, and at the same time be alert to the interference of factors that deviate from the "Dao."

\section{II. "Trouble OF BODY" AND “CONCERN BODY”}

Lao $\mathrm{Zi}$ pointed out in $13^{\text {th }}$ Chapter: "High rank is, like one's body, a source of great trouble." [5] In He Shang Gong's Commentaries on the Lao Zi 河上公章句, the term

${ }^{2}$ The translation of Laozi is form Lau, D. C., Dao Te Ching, Hong Kong: The Chinese University Press, 2001. Refer to original text from Boshu Lao Zi, Taibei: HEluo tushu chubanshe, 1975.

${ }^{3} \mathrm{Lao} \mathrm{Zi}$ chapter 25: Hence the way is great; Heaven is great; Earth is great; The king is also great. Within the realm, there are four things that are great, And the king counts as one. Man models himself on earth, Earth on heaven, Heaven on the way, And the way on that which is naturally so. 
“high rank (贵)" is interpreted as “fear (畏).” This sentence is then understood in such a way, "Once you have a body, you have to work hard, to worry about being protected from hunger and cold, and you will easily fall into desires when you touch them. This will inevitably lead to troubles." [6] Here the factors that deviate from the "Dao" is self-evident, namely the deliberate action (有为) and indulgence of human beings. Then it explained the term "no body," "the one who is detached from body, will follow a natural way of doing things. He will be able to easily ascend to heaven, and naturally enter between being and non-being, to be oneness with the Dao, thereby he will encounter no trouble." For the sentence in 13th Chapter of Lao Zi, "hence he who values his body more than dominion over the empire can be entrusted with the empire. He who loves his body more than dominion over the empire can be given the custody of the empire." It interpreted that if the empire cherishes himself then he will inevitably despise others, he will be able to temporarily keep his throne; The empire who cherishes himself will not only take care of his own interests, but will regard himself as the parents of all people, and he will be on the top of the people, then there will be no trouble for him. [6]

The above explanation reveals Daoist basic attitude towards the body and the path of cultivation. In fact, the human body is introduced as a negative point of view when it is the basis of a higher way of contemplation. In this sense, "abandoning body" is not an absolute but a relative statement. According to the view of Zhuangzi, the possession and depreciation of the body are not opposites. The body is the foundation of cultivation and the necessary condition for realizing the Dao. Since there is a "body", then one should first cherish it. The book Master Lü's Spring and Autumn Annals 吕氏春秋, which is based on Daoist thought, also recognized the preciousness of the body. It proposed that "the person who gets the body will get the personality, to lost the body is to lost personality." [7] The solution to the problem of "trouble of body" is to achieve "no body" by spiritual cultivation and eventually return to a natural state, the original state of unification with all things. Here, He Shang Gong's Commentaries on the Lao Zi implies the state after achieving the ultimate goal of Daoist cultivation and implies that people should not resort to action and should be detached from desire. The view in another important Daoist book Xiang'er's 想爾 Commentaries on Lao Zi, is consistent with the He Shang Gong's Commentaries on the $\mathrm{Lao} Z \mathrm{Zi}$, and it further illustrated the idea of attaining the Dao through “protecting the body (保身)" —— “holding the principles of Dao, accumulating good deeds as virtue, accumulating essence as spirit, transforming spirit into celestial being and immortal."

\section{THE ANALYSIS OF BODY}

\section{A. The Meaning of "Body"}

The body is a complex term. There are many words related to "body" mentioned in Lao $\mathrm{Zi}$, which can be summarized as the tangible (material) / the intangible (spiritual).

The word "body" appears as many as 22 times. Through analysis and interpretation, the word "body" has two meanings: one refers to the physical body of a person; the second means time, but only appears in the in the fifty-two chapters, zhongshen 终身, and moshen 没身, both means "to the end of one's days." The closest word to "body-person (身)" is "form (形)," ${ }^{4}$ which appears four times in the full text, all of which mean specific images and forms. This meaning is already included in the shen. Other terms such as the body, ears, mouth, heart, abdomen, tendons, bones, arms, etc. are also corresponding to the invisible "body," and interact and depend on one's spiritual consciousness, such as "the sage empties their minds but fills their bellies, weakens their wills but strengthens their bones." (Chapter 3) "For the belly, not for the eye." (Chapter 12), "taking up arms when there are no arms." (Chapter 69). By linking these terms to the full text, three conclusions can be drawn:

1) Lao $\mathrm{Zi}$ pays attention to the existence of the whole life which is not in a binary opposition. This unity refers not only to the unity of the body inside and outside, but also the unity of the body and the intangible and tangible things in outside world. It is also said that "hence the way is great; Heaven is great; Earth is great; The king is also great. Within the realm there are four things that are great, and the king counts as one.

Man models himself on earth, earth on heaven, heaven on the way, and the way on that which is naturally so." [8]

2) The body is the "personal body" of the "living body", not the corpse. This is contrary to the West. It is reflected in real life. The most typical example is the difference between Chinese and Western medicine. Traditional Chinese medicine presupposes the emphasis on the holistic view, while Western medicine mostly uses human corpses as specimens to cut and divide the human body system in order to classify and treat them.

3) The body is the transformation of "qi". Everything is made up of yin and yang, which have no gender, are merely a symbol or expression of a certain concept, which is of universal significance.

\section{B. Human Body and Dao}

The word "Dao (道)" first appeared in the Western Zhou Dynasty, and was composed of "shou (首)" (human head), "xing (行)" (walking), "zhi (止)" (toe) (Fig. 1), and some other notes add a "shou (手)" (hand), express a hand indication (Fig. 2), or add "zhua (爪)” (claw) and "yue (曰)" (speaking) to indicate hand-to-hand and speaking through mouth (Fig. 3). [9] This kind of figure-like form shows that "Dao" is related to the human body and refers to the whole body from head to toe. This point is fully reflected in Lao Zi. For instance, the "eye," "for the belly, not for the eye." (Chapter 12), the "mouth," "the way in its passage through

\footnotetext{
${ }^{4}$ The word "form" (形) is the closest to the whole "body-person"(身) in Lao Zi. The words similar to "shen 身" in modern language, such as "qu 身區" and "ti 體", do not appear in the text.
} 
the mouth." (Chapter 35); The "mind," "the sage in his attempt to distract the mind of the empire seeks urgently to muddle it. " (Chapter 49) The "essence," "this essence is quite genuine." (Chapter 21) All this kind of words refer to certain parts of the body and the way of all things. This shows that the Dao and the human body are inseparable.

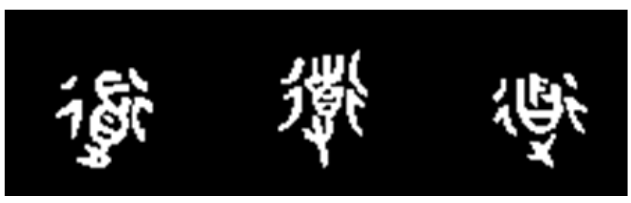

Fig.1 Fig.2 Fig.3

In addition, Lao $\mathrm{Zi}$ uses the metaphor of the "mother" (Chapter 1, 20, 25, 52 and 59) of all things to illustrate the nature of creation of the Dao, and the "mysterious female (玄牝)” symbolizes the female reproductive organs. He said, "The gateway of the mysterious female, is called the root of heaven and earth. Dimly visible, it seems as if it were there, yet use will never drain it." [10] It emphasizes that the Dao is the vitality of all things and runs through the whole life of human beings. If people perceive the Dao, they will be able to live forever. They will be like "babies" (Chapters 10, 20 and 49), like "a new born babe" (Chapter 55), weak, chaotic, unified, clear, no disturbance, full of energy. This is the "body" of the Dao.

\section{Body-person and Nature}

Nature is the attribute of the Dao, so it is called " Dao on the Nature." Nature has two meanings: one is the way in which everything is generated, and the other is the object of all things. It is said in chapter 42: " The Way (道) begets one; One begets two; Two begets three; Three begets the myriad creatures. The myriad creatures carry on their backs the yin and embrace in their arms the yang and are the blending of the generative forces of the two." [11] This sentence states the basic pattern of the creation of all things. Human beings is a kind of things and on the equality of things, such as Zhuang Zhou dreaming the butterfly, can be materialized, and naturally follows this pattern. It is only the person returning his "root" 根 that can discernment penetrates the four quarters and to the end of one's days one will meet with no danger. Besides, this sentence also points out that the composition of things is "qi". Qi is flowing in the body and between person and nature, so it can connect all the parts in the body and even person and nature. Therefore, Zhuang $\mathrm{Zi}$ reveals that "Listen not with your mind but with your primal breath...The primal breath, however, awaits things emptily." [12]

Lao $\mathrm{Zi}$ emphasizes the importance of nature, because "this is decreed by any authority but because it is natural for them to be treated so" (chapter 51). As long as the saint is "in order to help the myriad creatures to be natural and to refrain from daring to act "(Chapter 64), the ruler is "to use words but rarely and is to be natural." (Chapter 23), and it happened to the people naturally (Chapter 17), their tasks are accomplished and their work done. As for how to act in accordance with the principle of the law of nature, it is necessary to conform to the nature of person, which is like Liji Zhongyong 禮記・中庸, saying "Nature is the destiny of
Heaven, and Dao is the frankness of nature". [13] Only through cultivation can a person achieve the natural state of merging with the universe.

\section{Body-person is Heaven and Earth}

The Daoist view of the universe is based on the human self, by imaging the existence of an inner universe in the body to observe the outer universe. [14] Lao $\mathrm{Zi}$ believes that people should model himself on earth and heaven, and the body-person is a unity of heaven and earth. Huainanzi 淮南 子 has exerted the thought, figuratively describing that "the spirit of the person is subject to the heaven; and the body of the person is in accordance with the earth." [15] The growth of the human body is form following ten solar terms. The human body's five viscera correspond to the five directions according to their own principle, ${ }^{5}$ so "roundness of the head is like the heaven, and square of the foot is like the earth". [16] This is the very word "Dao" mentioned above which represents the whole body from head/top to fee/bottom, and the entire process from birth to death, performing the way of heaven and earth. This point has a specific portrayal in Zhuang Zi: "Whoever can take nonbeing as his head, life as his spine and death as his buttocks, whoever knows the oneness of life and death, of existence and nonexistence." [17] Neijing tu 內經圖 and Xiuzhen tu 修真圖 afterwards have brought this idea to the extreme, depicting the micro-universe inside the human body as a landscape, and each part corresponds to the principle of the macro-universe. [18] Lao Zi observes that " heaven and earth are enduring" (Chapter 9), so it is said that if people want to be immortal, they must follow the heaven and earth.

\section{CONCLUSION}

Body is a complex and even a huge research object, which has been noticed by both the East and West. Modern western scholars usually study the body as an "object". This thought of physical materialization concerned with the interaction and game between man and the real world. And its dualistic view separates man from the nature and universe, which bring material world and the spiritual world to distinguish. John O'Neill believes that the end of the universe's "anthropomorphism" is the consequence of modern people's "self" emphasizing abstraction and creativity. Body has lost the meaning of the basic blueprint, and is isolated and specialized in technical processing. [19] In addition, the body that the West knows depends on external forms to reveal its value. Because Westerners believe that it is difficult for people to achieve transcendence of their body through selves, they hope to carry out the top-down redemption and ascension of the body through God. God is full and innocent, but humans can never be separated from the power of God to transform themselves.

However, the understanding of the body has a very different landscape in Lao Zi. Lao $\mathrm{Zi}$ believes that the

${ }^{5}$ The so-called "five viscera" in the East refers to the interrelated organs systems, but not the physiological organs of five viscera in the West. See Huangdi Neijing and Huainanzi. 
human body and the universe are mutually analogous, and the body is the unity of time and space, material and spirit. In Dao's network of invisible images and borderless space-time, the body interacts with all the things and breathes together to form a large body field. [20] Therefore, the human body can establish a very self-sufficient world, capable of self-transformation, and at the same time can contain any gods and phenomena, and combine different cosmic systems. [21]

The content of Lao $\mathrm{Zi}$ is not a technical knowledge, but provides a theoretical framework. Thus it focuses on the integrity of the inner and outer universe and the unity of the Dao. The value of Lao Zi's body thought to the world lies in that it provides a more open and self-sufficient vision and builds a big net in which everyone is. The individual's body must be enlightened through individual practice to achieve the integration of the body's field, thus achieving the perfection and transcendence of the body.

\section{ACKNOWLEDGMENT}

We are thankful to Associate Professor Mark Meulenbeld, Dept. of Chinese Culture, Hong Kong Polytechnic University, who provided expertise that greatly assisted the research, although he may not agree with all of the interpretations provided in this paper.

We are also grateful to International Journal of Social Science and Humanity and its editors who moderated this paper and in that line improved the manuscript significantly.

\section{REFERENCES}

[1] Z. Yuchen, Shenti: sixiang yu xiuxing, Beijing: Zhongguo shehui kexue chubanshe, 2005, pp. 10.

[2] D. C. Lau, Dao Te Ching, Hong Kong: The Chinese University Press, 2001, pp. 37.

[3] D. C. Lau, Dao Te Ching, pp. 19.

[4] Wen Yiduo, Shenhua yu shi, Beijing: Zhonghua shuju, 1959, pp. 146.

[5] D. C. Lau, Dao Te Ching, pp. 19.
[6] Daozang, Beijing: Wenwu chubanshe; Shanghai: Shanghai shudian; Tianjin: Tianjin guji chubanshe, 1988, vol. 11, pp. 573.

[7] Gao You ed., Lüshi chunqiu, Qing Sibucongkan jingmingkanben, vol. 26, pp.22.

[8] D. C. Lau, Dao Te Ching, pp. 39.

[9] CHANT (Chinese Ancient Texts) [Online]. Available: http://www.chant.org/Database.aspx.

[10] D. C. Lau, Dao Te Ching, pp. 9.

[11] D. C. Lau, Dao Te Ching, chapter 42.

[12] Roger T. Ames, Wandering at Ease in the Zhuangzi, Albany: SUNY Press, 1998, pp.32.

[13] Z. Xi, Sishuzhangju jizhu, Beijing: Zhonghua shuju, 2016, pp.17.

[14] K. M. Schipper, "Laozi zhongjing chutan," Daoist Culture Study, vol. 16, April 1999, pp. 204

[15] Y. Zhengxie, Guisi cungao Qing Daoguang Lingshike Lanyunyi congshuben, vol. 4, pp. 66.

[16] Liu An, Xu Shen note, Huainan honglie jie, Sibucongkan jingchao Beisong ben, vol. 6, pp.76.

[17] R. T. Ames, Wandering at Ease in the Zhuangzi, pp. 57-58.

[18] K. M. Schipper, The Daoist Body, Berkeley: University of California Press, 1993, pp.108-112.

[19] J. O'Neill, Five Bodies: The Human Shape of Modern Society, Ithaca: Cornell Univ Pr, 1985, pp. 122-123.

[20] W. Zhimei, "Cong yushen dao wushen, lun laozi de shentiguan," Guowen xuezhi, No. 15, pp. 46, 2007.

[21] K. M. Schipper, "Laozi zhongjing chutan," Daoist Culture Study, vol. 16, pp. 215-216, April 1999.

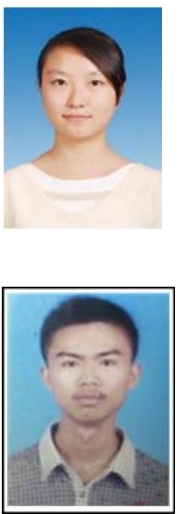

Zeng Weijie, who was born in July 1990, is currently a master student of Dept. of Chinese Culture, Hong Kong Polytechnic University.

She is currently working as a part-time teaching assistant in Dept. of Chinese Culture, Hong Kong Polytechnic University. Her current research interests include Daoism, and Folk Belief and Occult. Kong Polytechnic University. His current research interests include Chinese religion and Japanese Buddhism. 